\title{
Spatial Autoregressive Model untuk Pemodelan Angka Harapan Hidup (AHH) di Provinsi Jawa Timur
}

\author{
Nova Ratih Intan ${ }^{(1)}$, Edy Sulistiyawan ${ }^{(2)}$ \\ 1,2) Universitas PGRI Adi Buana Surabaya \\ Jl. Dukuh Menanggal XII Telp./Fax. (031) 822289873 Surabaya 60234 \\ e-mail: novaratihintanlestari@gmail.com dan warapra@unipasby.ac.id
}

\begin{abstract}
ABSTRAK
Angka Harapan Hidup adalah perkiraan usia hidup yang dapat dicapai oleh penduduk pada suatu wilayah. Angka harapan hidup digunakan sebagai salah satu indikator derajat kesehatan masyarakat suatu negara. Angka harapan hidup juga dapat menjadi tolak ukur untuk mengevaluasi kinerja pemerintah dalam bidang kesehatan, sosial dan ekonomi. Oleh karena itu diperlukan sebuah pemodelan statistika untuk menganalisis faktor-faktor yang mempengaruhi angka harapan hidup di Jawa Timur. Analisis data menggunakan metode regresi linear berganda dengan pendekatan Ordinary Least Square (OLS) tidak cukup jika beberapa asumsi OLS tidak terpenuhi. Maka untuk mengatasi hal tersebut digunakan metode Spatial Autoregressive Model (SAR) yang digunakan untuk mengetahui lag spasial pada variabel respon dan menaksir parameter. Berdasarkan hasil analisis, pada aspek spasial data telah memenuhi asumsi dependensi spasial menggunakan uji Moran's I dengan p-value sebesar 0,004315. Matriks pembobot yang digunakan adalah matriks pembobot Queen Contiguity. Diperoleh nilai koefisien determinasi $\left(\mathrm{R}^{2}\right)$ dan Akaike's Information Criterion (AIC) dari Spatial Autoregressive Model yang lebih baik dari OLS berturut-turut yaitu 72,459\% dan 137,36. Faktor signifikan yang mempengaruhi AHH di setiap kabupaten/kota di Jawa Timur adalah persentase rumah tangga berperilaku hidup bersih dan sehat $\left(\mathrm{X}_{7}\right)$ dan persentase penduduk miskin $\left(\mathrm{X}_{8}\right)$.

Kata kunci : Angka Harapan Hidup, Regresi Linier Berganda, Moran's I, Spatial Autoregressive Model.
\end{abstract}

\section{ABSTRACT}

Life expectancy is an estimation of life spans that can be attained in a region. Life expectancy is an indicator of the amount of a country's public health. Life expectancy also can be a benchmark for evaluating the government's performance in health, social and economic fields. So, we need a statistic model to analyze the factors that affect life expectancy in East Java. The data analysis using multiple linear regression method with Ordinary Least Square (OLS) approach is not enough if some of OLS assumption is not fulfilled. That is why to overcome that problem we use Spatial Autoregressive Model (SAR) method which is used to know the spatial lag on variable response and parameter estimate. According to the data analysis, on the spatial aspect the data has fulfilled the assumption of spatial dependency using Moran's I with p-value of 0,004315. The spatial weighted matrices that is used is weighted matrices Queen Contiguity. There is the coefficient of determination value $\left(R^{2}\right)$ and Akaike's Information Criterion (AIC) from Spatial Autoregressive Model that is better than OLS consecutively that is $72,459 \%$ and 137,36 . The significant factor that affect life expectancy on every region/city in East Java is the percentage of households that live clean and health $\left(X_{7}\right)$ and the percentage of poor people $\left(X_{8}\right)$.

Keywords : Life Expectancy, Multiple Linier Regression, Moran's I, Spatial Autoregressive Model.

\section{PENDAHULUAN}

Analisis regresi merupakan salah satu teknik statistik yang digunakan secara luas pada ilmu terapan untuk menyelesaikan masalah sebab akibat. Analisis regresi tersebut merupakan suatu metode yang digunakan untuk menganalisis hubungan antar variabel yang dibentuk dalam suatu persamaan atau regresi. Regresi memiliki bermacam-macam bentuk seperti, regresi linear sederhana dan regresi linear berganda yang digunakan untuk mencari hubungan linear antara variabel prediktor dan variabel respon. Kemudian, regresi data panel yang merupakan regresi bagi data cross section atau runtun waktu. 
Adapula regresi spasial yang merupakan regresi bagi data yang memiliki efek spasial.

Regresi spasial merupakan hasil pengembangan dari metode regresi linear klasik. Pengembangan tersebut karena adanya pengaruh tempat atau spasial pada data yang dianalisis. Sehingga, jika terdapat data dengan efek spasial maka analisis yang digunakan adalah analisis regresi spasial.

Regresi spasial memiliki beberapa model utama yaitu Spatial Autoregressive Model (SAR), Spatial Error Model (SEM) dan Spatial Autoregressive Moving Average (SARMA). Spatial Autoregressive Model merupakan suatu model yang paling mudah dan paling sederhana dari model spatial (Anselin, 2005). Model ini diusulkan oleh Whittle pada tahun 1945. Spatial Autoregressive Model ditentukan berdasarkan nilai kedekatan suatu wilayah dengan wilayah tetangganya (Ward dan Gledist, 2008). Spatial Autoregressive Model menunjukkan keterkaitan antara suatu wilayah dengan wilayah lain yang berdekatan.

Pada pemodelan regresi dengan efek spasial, maka harus disusun sebuah matriks pembobot spasial untuk mengetahui interaksi spasial yang terjadi antar wilayah satu dengan wilayah lainnya. Jika interaksi antar wilayah berdasarkan pada persinggungan sisi wilayah maka matriks pembobot spasial yang terbentuk adalah rook contiguity. Jika interaksi antar wilayah berdasarkan persinggungan titik sudut maka matriks pembobot spasial yang terbentuk adalah bishop contiguity. Sedangkan apabila interaksi antar wilayah merupakan gabungan dari persinggungan sisi wilayah dan titik sudut, maka matriks pembobot spasial yang terbentuk adalah queen contiguity.

Angka Harapan Hidup (AHH) adalah perkiraan usia hidup yang dapat dicapai oleh penduduk pada suatu wilayah (Haryati dkk, 2007). Tinggi rendahnya AHH menjadi salah satu kriteria penggolongan negara maju dan negara berkembang. Negara maju cenderung memiliki AHH lebih tinggi dibandingkan dengan negara berkembang maupun negara tertinggal. Indonesia merupakan negara berkembang dengan nilai AHH diantara 64 tahun sampai 71 tahun pada tahun 1990 sampai tahun 2012 dan berada dalam urutan ke-117 dari 222 negara di dunia pada tahun 2013 (WHO, 2013). AHH digunakan sebagai salah satu indikator derajat kesehatan masyarakat suatu negara. Derajat kesehatan masyarakat adalah tingkat kesehatan yang mungkin pada suatu periode sesuai kondisi, situasi, dan kemampuan masyarakat (Sibarani, 2013). Derajat kesehatan masyarakat dapat ditingkatkan melalui program-program kesehatan yang diberikan pemerintah kepada masyarakat. Oleh karena itu,
AHH dapat menjadi tolak ukur untuk mengevaluasi kinerja pemerintah dalam bidang kesehatan, sosial dan ekonomi.

Berdasarkan uraian di atas, peneliti tertarik untuk melakukan penelitian dengan judul "Spatial Autoregressive Model Untuk Pemodelan Angka Harapan Hidup (AHH) di Provinsi Jawa Timur". Tujuan dari penelitian ini adalah untuk mengetahui deskriptif Angka Harapan Hidup dan model terbaik pemodelan Angka Harapan Hidup di Provinsi Jawa Timur dengan Spatial Autoregressive Model.

\section{METODE PENELITIAN}

Analisis yang digunakan dalam penelitian ini yaitu analisis regresi linear berganda dan Spatial Autoregressive Model. Langkah-langkah dalam penelitian ini adalah sebagai berikut:

1. Mendeskripsikan Angka Harapan Hidup di Jawa Timur.

2. Memodelkan Angka Harapan Hidup dengan regresi linear berganda.

3. Menguji asumsi model regresi linear berganda (asumsi residual identik, asumsi residual independen dan asumsi residual berdistribusi normal) dan pengujian multikolinearitas.

4. Menyusun pembobot spasial dengan matriks pembobot Queen Contiguity.

5. Menguji dependensi spasial atau korelasi antar pengamatan yang saling berdekatan dengan Moran's $I$.

6. Menguji $\rho \neq 0$ dengan uji Lagrange Multiplier untuk melakukan pemodelan Spatial Autoregressive Model.

7. Memodelkan Angka Harapan Hidup dengan Spatial Autoregressive Model.

8. Menguji asumsi pada Spatial Autoregressive Model, yaitu asumsi residual identik, asumsi residual independen dan asumsi residual berdistribusi normal.

9. Menentukan model terbaik dengan kriteria $\mathrm{R}^{2}$ dan AIC.

10. Interpretasi model.

\section{HASIL DAN PEMBAHASAN}

\subsection{Analisis Deskriptif}

Karakteristik variabel yang digunakan dapat diketahui melalui nilai rata-rata angka harapan hidup di Jawa Timur termasuk dalam kriteria cukup tinggi yaitu setiap satu anak lahir di Jawa Timur mempunyai rata-rata tahun akan dijalani sebesar 71,05 tahun atau mendekati 71 tahun pada tahun 2016, terdapat 17 kabupaten/kota di Jawa Timur yang memiliki AHH lebih kecil dari rata-rata dan 21 kabupaten/kota di Jawa Timur yang memiliki AHH 
lebih besar dari rata-rata. Pada Tabel 1 ditunjukkan nilai minimum $\mathrm{AHH}$ sebesar 65,89 yaitu di Kabupaten Bondowoso dan nilai maksimum $\mathrm{AHH}$ sebesar 73,87 yaitu di Kabupaten Surabaya, variabel AHH menjadi variabel dengan nilai varians yang paling rendah dibandingkan variabel lainnya yaitu sebesar 2,90

Tabel 1. Statistik Deskriptif Variabel Penelitian

\begin{tabular}{crrrr}
\hline Variabel & $\begin{array}{c}\text { Rata- } \\
\text { rata }\end{array}$ & $\begin{array}{c}\text { Koefisien } \\
\text { Varians }\end{array}$ & \multicolumn{1}{c}{ Min } & \multicolumn{1}{c}{ Max } \\
\hline $\mathrm{Y}$ & 71,05 & 2,90 & 65,89 & 73,87 \\
\hline $\mathrm{X}_{1}$ & 73,40 & 11,12 & 55,20 & 88,20 \\
\hline $\mathrm{X}_{2}$ & 101,62 & 26,85 & 50,02 & 202,94 \\
\hline $\mathrm{X}_{3}$ & 94,74 & 3,28 & 87,40 & 99,90 \\
\hline $\mathrm{X}_{4}$ & 0,21 & 85,71 & 0,00 & 0,68 \\
\hline $\mathrm{X}_{5}$ & 75,72 & 25,55 & 20,30 & 114,46 \\
\hline $\mathrm{X}_{6}$ & 67,36 & 30,57 & 13,00 & 100,00 \\
\hline $\mathrm{X}_{7}$ & 49,64 & 29,77 & 19,40 & 75,10 \\
\hline $\mathrm{X}_{8}$ & 11,87 & 40,69 & 4,33 & 24,11 \\
\hline $\mathrm{X}_{9}$ & 0,60 & 55,00 & 0,06 & 1,60 \\
\hline $\mathrm{X}_{10}$ & 1926,88 & 120,29 & 282,08 & 8770,43 \\
\hline
\end{tabular}

Pembagian AHH di Jawa Timur menjadi 5 kategori yaitu sangat rendah, rendah, sedang, tinggi, dan sangat tinggi. Berdasarkan Gambar 1 secara visual dapat terlihat bahwa angka harapan hidup menunjukkan pola mengelompok.

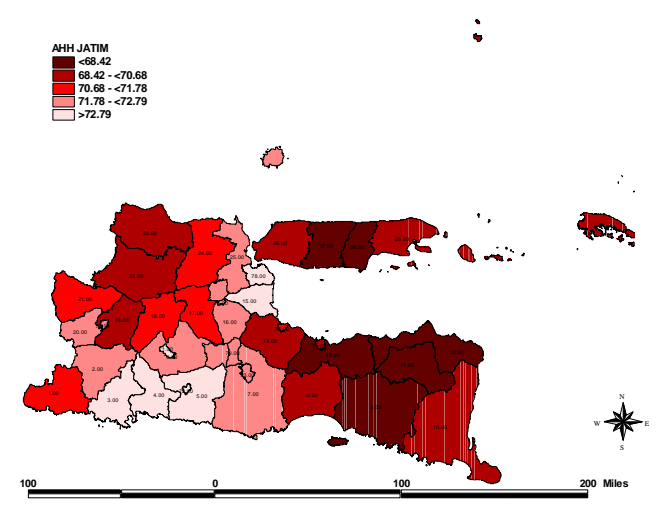

Gambar 1. Persebaran Angka Harapan Hidup di Jawa Timur tahun 2016

Berdasarkan Gambar 1, dapat diketahui bahwa pola persebaran angka harapan hidup dengan warna lokasi yang semakin terang menunjukkan semakin tingginya angka harapan hidup di lokasi tersebut. Angka harapan hidup kategori sangat tinggi berada pada angka diatas 72,79 yang terdapat di empat kabupaten dan tiga kota yaitu Kabupaten Trenggalek, Kabupaten Tulungagung, Kabupaten Blitar, Kabupaten Sidoarjo, Kota Kediri, Kota
Blitar, dan Kota Surabaya. Angka harapan hidup kategori tinggi berada diantara angka 71,78 $<72,79$ yang terdapat di enam kabupaten dan empat kota yaitu Kabupaten Ponorogo, Kabupaten Kediri, Kabupaten Malang, Kabupaten Mojokerto, Kabupaten Magetan, Kabupaten Gresik, Kota Malang, Kota Mojokerto, Kota Madiun, dan Kota Batu. Angka harapan hidup kategori sedang berada diantara angka 70,68 - <71,78 yang terdapat di lima kabupaten dan satu kota yaitu Kabupaten Pacitan, Kabupaten Jombang, Kabupaten Nganjuk, Kabupaten Ngawi, Kabupaten Lamongan, dan Kota Pasuruan. Angka harapan hidup kategori rendah berada diantara angka 68,42 - <70,68 yang terdapat di delapan kabupaten dan satu kota yaitu Kabupaten Lumajang, Kabupaten Banyuwangi, Kabupaten Pasuruan, Kabupaten Madiun, Kabupaten Bojonegoro, Kabupaten Tuban, Kabupaten Bangkalan, Kabupaten Sumenep, dan Kota Probolinggo. Sedangkan warna lokasi yang semakin gelap menunjukkan angka harapan hidup dengan kategori sangat rendah berada pada angka dibawah 68,42 yang terdapat di enam kabupaten yaitu Kabupaten Jember, Kabupaten Bondowoso, Kabupaten Situbondo, Kabupaten Probolinggo, Kabupaten Sampang, dan Kabupaten Pamekasan

\subsection{Model Regresi Linier Berganda}

Hasil pengujian parameter secara serentak diperoleh nilai $F_{\text {hitung }}$ sebesar 3,519 dan p-value sebesar 0,004435 sehingga $\mathrm{H}_{0}$ ditolak karena $\mathrm{F}_{\text {hitung }}$ lebih besar dari $F_{\text {tabel }}(2,20)$ dan $p$-value lebih kecil dari $\alpha$ sebesar 5\%. Oleh karena itu, dapat disimpulkan bahwa variabel-variabel prediktor secara serentak berpengaruh terhadap variabel respon.

Selanjutnya dilakukan pengujian parameter secara parsial untuk mengetahui variabel mana saja yang berpengaruh secara signifikan terhadap variabel respon. Berdasarkan Tabel 2 diketahui variabel yang berpengaruh secara signifikan terhadap variabel respon adalah yang memiliki $p$ value $<\alpha$. Dengan taraf signifikansi 5\% maka diperoleh dua variabel prediktor yang berpengaruh secara signifikan terhadap variabel respon yaitu variabel rumah tangga berperilaku hidup bersih dan sehat $\left(X_{7}\right)$ dan variabel penduduk miskin $\left(X_{8}\right)$.

Dari Tabel 2 diperoleh persamaan regresi linear berganda sebagai berikut.

$\hat{y}=0,7450-0,0007 \mathrm{X}_{i 1}-0,0000 \mathrm{X}_{i 2}-0,0007 \mathrm{X}_{i 3}-$ $0,3192 \mathrm{X}_{i 4}+0,0004 \mathrm{X}_{i 5}-0,0003 \mathrm{X}_{i 6}+0,0042 \mathrm{X}_{i 7}-$ $0,0246 \mathrm{X}_{i 8}-0,1186 \mathrm{X}_{i 9}-0,0000 \mathrm{X}_{i 10}$

Diperoleh nilai koefisien determinasi $\left(\mathrm{R}^{2}\right)$ sebesar 0,5658 yang berarti sebesar $56,58 \%$ variasi $\mathrm{AHH}$ dapat dijelaskan oleh variabel prediktor yang 
telah ditentukan, sedangkan sisanya 43,42\% dijelaskan oleh variabel lainnya yang tidak dimasukkan kedalam model regresi dalam penelitian ini.

Tabel 2. Hasil Uji Parameter secara Parsial

\begin{tabular}{crrr}
\hline Parameter & Koefisien & t-value & \multicolumn{1}{c}{$\boldsymbol{p}$-value } \\
\hline$\hat{\beta}_{0}$ & 0,7450 & 8,171 & $* 0,0000$ \\
\hline$\hat{\beta}_{1}$ & $-0,0007$ & $-0,155$ & 0,8782 \\
\hline$\hat{\beta}_{2}$ & $-0,0000$ & $-0,009$ & 0,9931 \\
\hline$\hat{\beta}_{3}$ & $-0,0006$ & $-0,077$ & 0,9395 \\
\hline$\hat{\beta}_{4}$ & $-0,3192$ & $-1,833$ & 0,0778 \\
\hline$\hat{\beta}_{5}$ & 0,0004 & 0,191 & 0,8501 \\
\hline$\hat{\beta}_{6}$ & $-0,0003$ & $-0,119$ & 0,9064 \\
\hline$\hat{\beta}_{7}$ & 0,0042 & 2,107 & $* 0,0446$ \\
\hline$\hat{\beta}_{8}$ & $-0,0246$ & $-2,845$ & $* 0,0084$ \\
\hline$\hat{\beta}_{9}$ & $-0,1186$ & $-1,178$ & 0,2493 \\
\hline$\hat{\beta}_{10}$ & $-0,0000$ & $-0,415$ & 0,6811
\end{tabular}

*signifikan pada $\alpha=5 \%(0,05)$

Untuk uji asumsi model regresi linier berganda dilakukan sebanyak tiga kali pengujian, yaitu uji identik, independen, dan uji distribusi normal. Dari ketiga pengujian yang dilakukan, diperoleh hasil bahwa data memenuhi ketiga asumsi yaitu identik, independen, dan distribusi normal.

\subsection{Multikolinieritas}

Pada Tabel 3 menunjukkan bahwa nilai VIF dari masing-masing variabel yaitu kurang dari 10 yang artinya tidak terdapat multikolinearitas pada masing-masing variabel prediktor.

Tabel 3. Nilai VIF Variabel Prediktor

\begin{tabular}{crcr}
\hline Variabel & Nilai VIF & Variabel & Nilai VIF \\
\hline $\mathrm{X}_{1}$ & 2,2286 & $\mathrm{X}_{6}$ & 4,1139 \\
\hline $\mathrm{X}_{2}$ & 1,2944 & $\mathrm{X}_{7}$ & 1,2715 \\
\hline $\mathrm{X}_{3}$ & 1,1775 & $\mathrm{X}_{8}$ & 2,5664 \\
\hline $\mathrm{X}_{4}$ & 1,4460 & $\mathrm{X}_{9}$ & 1,6368 \\
\hline $\mathrm{X}_{5}$ & 2,7714 & $\mathrm{X}_{10}$ & 2,5826 \\
\hline
\end{tabular}

\subsection{Matriks Pembobot Spasial dengan Matriks Quwwn Contiguity}

Matriks pembobot spasial yang digunakan dalam penelitian ini yaitu pembobot spasial dengan matriks Queen Contiguity yang merupakan gabungan antara Rook Contiguity (persinggungan sisi) dengan Bishop Contiguty (persinggungan sudut) dengan matriks berukuran $38 \times 38$.

\subsection{Uji Efek Dependensi Spasial}

Terdapat dua pengujian efek dependensi spasial, yaitu uji moran's I dan uji Lagrange
Multiplier. Hasil pengujian Moran's I diperoleh $p$ value sebesar 0,004315 yang lebih kecil dari $\alpha$ sebesar 5\% maka tolak $\mathrm{H}_{0}$ sehingga terdapat autokorelasi pada model atau ada ketergantungan antar lokasi. Karena nilai autokorelasi bernilai positif, maka pola datanya mengelompok (cluster). Dengan demikian, analisis regresi spasial untuk mengatasi autokorelasi spasial pada kasus Angka Harapan Hidup di Jawa Timur dapat dilakukan.

Pengujian selanjutnya yaitu Lagrange Multiplier. Hasil pengujian terdapat pada Tabel 4 yang menunjukkan $p$-value dari masing-masing model spasial kurang dari $\alpha$ sebesar 5\%, maka tolak $\mathrm{H}_{0}$ yang artinya pada masing-masing model terdapat efek spasial. Akan tetapi, model yang dipilih dengan $p$-value yang paling kecil yaitu $p$ value Lagrange Multiplier (lag) sebesar 0,0000026 lebih kecil dari $\alpha$ sebesar $5 \%$ maka tolak $\mathrm{H}_{0}$ sehingga terdapat autokorelasi spasial lag pada variabel respon dan perlu dilanjutkan pembentukan model dengan Spatial Autoregressive Model (SAR).

Tabel 4. Hasil Uji Lagrange Multiplier

\begin{tabular}{lrr}
\hline \multicolumn{1}{c}{ Uji Spasial Dependensi } & \multicolumn{1}{c}{ Nilai } & \multicolumn{1}{c}{ p-value } \\
\hline Lagrange Multiplier (lag) & 17,716 & 0,0000026 \\
\hline Lagrange Multiplier (error) & 4,485 & 0,03419 \\
\hline Lagrange Multiplier (SARMA) & 20,341 & 0,0000038 \\
\hline
\end{tabular}

3.6 Spatial Autoregressive Model (SAR)

Langkah selanjutnya memodelkan Spatial Autoregressive Model (SAR) dengan melakukan estimasi dan pe-ngujian parameter untuk mengetahui parameter yang signifikan.

Tabel 5. Hasil Estimasi dan Pengujian Parameter Spatial Autoregressive Model

\begin{tabular}{ccc}
\hline Parameter & Koefisien & $\boldsymbol{p}$-value \\
\hline$\rho$ & 0,50476 & $* 0,000002$ \\
\hline$\hat{\beta}_{0}$ & 36,14974 & 0,001152 \\
\hline$\hat{\beta}_{1}$ & $-0,02517$ & 0,485119 \\
\hline Parameter & Koefisien & $\boldsymbol{p}$-value \\
\hline$\hat{\beta}_{2}$ & $-0,00225$ & 0,782717 \\
\hline$\hat{\beta}_{3}$ & 0,03115 & 0,652240 \\
\hline$\hat{\beta}_{4}$ & $-1,19796$ & 0,386274 \\
\hline$\hat{\beta}_{5}$ & $-0,00445$ & 0,791616 \\
\hline$\hat{\beta}_{6}$ & $-0,00295$ & 0,876482 \\
\hline$\hat{\beta}_{7}$ & 0,03676 & $* 0,014238$ \\
\hline$\hat{\beta}_{8}$ & $-0,18592$ & $* 0,005018$ \\
\hline$\hat{\beta}_{9}$ & $-0,63976$ & 0,403036 \\
\hline$\hat{\beta}_{10}$ & $-0,00006$ & 0,640090 \\
\hline$*$ signifikan pada $\alpha=5 \%(0,05)$
\end{tabular}

Nova Ratih Intan Lestari ${ }^{1}$, Edy Sulistiyawan ${ }^{2}$ / J Statistika Vol.11, No.2, (2018) 
Pada Tabel 5, diperoleh model persamaan Spatial Autoregressive Model (SAR) sebagai berikut.

$$
\hat{y}_{\mathrm{i}}=36,14974+0,50476 \sum_{j=1, i \neq j}^{n} w_{i j} y_{j}-0,02517 \mathrm{X}_{i 1}-
$$

$0,00225 \mathrm{X}_{i 2}+0,03115 \mathrm{X}_{i 3}-1,19796 \mathrm{X}_{i 4}-0,00445 \mathrm{X}_{i 5}$

$-0,00295 \mathrm{X}_{i 6}+0,03676 \mathrm{X}_{i 7}-0,18592 \mathrm{X}_{i 8}-$ $0,63976 \mathrm{X}_{i 9}-0,00006 \mathrm{X}_{i 10}$

Terdapat dua variabel yang memiliki $p$-value lebih kecil dari $\alpha$ sebesar 5\% yaitu variabel rumah tangga berperilaku hidup bersih dan sehat $\left(\mathrm{X}_{7}\right)$ dan variabel penduduk miskin $\left(\mathrm{X}_{8}\right)$ (Tabel 5). Sehingga dapat disimpulkan bahwa kedua variabel tersebut memiliki pengaruh yang signifikan terhadap variabel angka harapan hidup. Selanjutnya dilakukan uji asumsi pada regresi spasial tersebut. Pengujian asumsi pada model SAR diantaranya uji residual identik, uji residual independen, dan uji residual berdistribusi normal.

Tabel 6. Uji Asumsi Residual Spatial Autoregressive Model

\begin{tabular}{llrr}
\hline \multicolumn{1}{c}{ Uji } & \multicolumn{1}{c}{ Metode } & Nilai & \multicolumn{1}{c}{ p-value } \\
\hline Identik & Breusch-Pagan & 12,537 & 0,251 \\
\hline Independen & Durbin-Watson & 2,199 & $* 0,141$ \\
\hline $\begin{array}{l}\text { Distribusi } \\
\text { Normal }\end{array}$ & $\begin{array}{l}\text { Kolmogorov- } \\
\text { Smirnov }\end{array}$ & 0,141 & 0,056 \\
\hline
\end{tabular}

*diwakili nilai $\mathrm{D}_{\text {hitung }}$

Berdasarkan Tabel 6 diperoleh $p$-value BP sebesar 0,251 yang lebih besar dari nilai $\alpha$ sebesar $5 \%$ maka gagal tolak $\mathrm{H}_{0}$ sehingga ragam residual pada model homogen atau tidak terjadi efek heteroskedastisitas. Dengan demikian, asumsi residual identik telah terpenuhi.

Nilai Durbin-Watson seperti yang tersaji pada Tabel 6 sebesar 2,199, sedangkan dari tabel dW dengan signifikansi $5 \%$ dengan $\mathrm{n}=38$ dan $\mathrm{k}=10$ diperoleh nilai $\mathrm{dL}$ sebesar 0,9118 dan $\mathrm{dU}$ sebesar 2,1803. Karena nilai Durbin-Watson lebih besar dari dL maka gagal tolak $\mathrm{H}_{0}$ sehingga dapat disimpulkan bahwa tidak terdapat autokorelasi atau residual independen. Dengan demikian, asumsi residual independen telah terpenuhi.

Tabel 6 menunjukkan bahwa residual telah berdistribusi normal, karena diperoleh $\mathrm{D}_{\text {hitung }}$ sebesar 0,141, sedangkan pada tabel KolmogorovSmirnov dengan signifikansi 5\% dan $\mathrm{n}=38$ diperoleh nilai $D_{\text {tabel }}$ sebesar 0,215 . Berdasarkan nilai $\mathrm{D}_{\text {hitung }}$ yang lebih kecil dari $\mathrm{D}_{\text {tabel }}$ atau $p$-value sebesar 0,056 yang lebih besar dari $\alpha$ sebesar 5\% maka gagal tolak $\mathrm{H}_{0}$ sehingga data yang digunakan memenuhi asumsi residual berdistribusi normal.

Model SAR merupakan model tepat untuk menggambarkan AHH di Provinsi Jawa Timur karena mempunyai nilai AIC terkecil dan nilai $\mathrm{R}^{2}$ terbesar diantara model regresi OLS.

Tabel 7. Hasil nilai $\mathrm{R}^{2}$ dan AIC

\begin{tabular}{lcc}
\hline Model & $\mathbf{R}^{2}$ & AIC \\
\hline OLS & $56,58 \%$ & 154,06 \\
\hline SAR & $73,46 \%$ & 137,36 \\
\hline
\end{tabular}

\section{KESIMPULAN DAN SARAN}

Berdasarkan hasil analisis dan pembahasan didapatkan kesimpulan bahwa:

1. Rata-rata angka harapan hidup di Jawa Timur dikatakan cukup tinggi yaitu setiap satu anak lahir di Jawa Timur mempunyai rata-rata tahun akan dijalani sebesar 71,05 tahun atau mendekati 71 tahun pada tahun 2016, terdapat 17 kabupaten/kota di Jawa Timur yang memiliki AHH lebih kecil dari rata-rata dan 21 kabupaten/kota di Jawa Timur yang memiliki AHH lebih besar dari rata-rata.

Pembagian AHH di Jawa Timur menjadi 5 kategori yaitu sangat rendah, rendah, sedang, tinggi, dan sangat tinggi dan menunjukkan pola mengelompok. Pola persebaran angka harapan hidup dengan warna lokasi yang semakin terang menunjukkan semakin tingginya angka harapan hidup di lokasi tersebut, sedangkan warna lokasi yang semakin gelap menunjukkan angka harapan hidup dengan kategori sangat rendah di lokasi tersebut.

2. Hasil analisis Spatial Autoregressive Model (SAR) dengan matriks pembobotnya adalah Queen Contiguity, terlebih dahulu dilakukan analisis regresi linear berganda dan diperoleh hanya dua variabel prediktor yang signifikan dan asumsi residual terpenuhi. Selanjutnya dilakukan pembobotan spasial dan diperoleh uji Lagrange Multiplier dengan $p$-value paling signifikan yaitu Lagrange Multiplier (lag), maka dilanjutkan ke pemodelan Spatial Autoregressive Model (SAR). Persamaan regresi dugaan dengan model SAR yang diperoleh adalah sebagai berikut.

$$
\begin{array}{llcl}
\hat{y}_{\mathrm{i}}=36,14973847 & + & 0,50476 \sum_{j=1, i \neq j}^{n} w_{i j} y_{j} & - \\
0,02517462 \mathrm{X}_{i 1} & - & 0,00225486 \mathrm{X}_{i 2} & + \\
0,03114890 \mathrm{X}_{i 3} & - & 1,19796437 \mathrm{X}_{i 4} & - \\
0,00444997 \mathrm{X}_{i 5} & - & 0,00295198 \mathrm{X}_{i 6} & + \\
0,03676341 \mathrm{X}_{i 7} & - & 0,18592314 \mathrm{X}_{i 8} & - \\
0,63976585 \mathrm{X}_{i 9}-0,00006354 \mathrm{X}_{i 10} &
\end{array}
$$

dengan persentase rumah tangga berperilaku hidup bersih dan sehat $\left(\mathrm{X}_{7}\right)$ dan persentase penduduk miskin $\left(\mathrm{X}_{8}\right)$ yang memiliki pengaruh signifikan 
J Statistika Vol. 11, No. 2,(2018), Hal. 37-42

terhadap variabel respon yaitu angka harapan hidup. Koefisien determinasi $\left(\mathrm{R}^{2}\right)$ dan Akaike's Information Criterion (AIC) yang dihasilkan regresi spasial dengan SAR berturut-turut yaitu 72,459\% dan 137,36 sehingga model dianggap cukup baik.

Berdasarkan hasil penelitian yang diperoleh, maka ada beberapa saran yang dapat dikemukakan yaitu sebagai berikut:

1. Pada penelitian ini membahas model regresi spasial hanya pada data cross section dengan kasus kemiskinan di kabupaten/kota Jawa Timur, diharapkan pada penelitian selanjutnya dapat dikembangkan dengan menggunakan data panel.

2. Pengujian asumsi residual independen pada penelitian ini tidak terpenuhi, diharapkan dalam penelitian selanjutnya dimungkinkan ada metode lain yang dapat mengatasi asumsi independen yang terlanggar.

\section{DAFTAR PUSTAKA}

Anselin, Luc., (1988), Spatial Econometrics: Methods and Models, Dordrecht: Kluwer Academic Publishers.

Anselin, Luc., (2005), Spatial Regression Analysis in $R$, University of Illions, Urbana Champaign.

Dinas Kesehatan. (2017). Profil Kesehatan Provinsi Jawa Timur Tahun 2016. Surabaya.

Drapper, N. R. and Smith, H., (1992), Analisis Regresi Terapan, Edisi Kedua, Terjemahan oleh Bambang Sumantri, Jakarta: Gramedia Pustaka Utama.

LeSage, J. P., (1999), The Theory and Practice of Spatial Econometrics, Toledo: Department of Economics, University of Toledo.

LeSage, J. P., Pace, R. K., (2009), Introduction to Spatial Econometrics, Boca Raton: CRC Press.

M. D. Ward and K. S. Gleditsch, (2008), Spatial Regression Model, California: Sage Publications, Inc.

WHO. (2013). Life expectancy: Life expectancy

Data by country [Internet]. World Health

Organization.Tersedia pada

http://apps.who.int/gho/data/node.main.688?

ang=en. Diakses tanggal 22 Januari 2018. 